\title{
Self Help Group Analysis of Self Esteem and Stress Levels in Families with Patients with Depression
}

\section{Errix Kristian Julianto}

Institut Ilmu Kesehatan STRADA

Indonesia, Kediri, Indonesia

Email:

Kristian.Errix@gmail.com

\begin{abstract}
Increasing cases of depression and stress each year are related to increasing rates of divorce, academic or employment demands and social pressure. Not infrequently families who have family members who experience depression make it a family burden. Family perception of the stressor will affect the level of burden in the family and can affect the level of stress and family self esteem. The purpose of this study was to analyze the effect of Self Help Group on self esteem and Stress levels on Families with Depression at the Poly Psychology of the Kalitidu Health Center. The design of this study was True experimental with pre-posttest design. The sampling technique uses simple random sampling as many as 32 respondents, with 16 control group respondents and 16 family respondents with depressed patients who received a Self Help group. Data analysis techniques using Wilcoxon statistical test and mannwhitny. The results of this study indicate that there is an effect of self help group on self esteem and stress levels in families with depressed patients in mental health clinics of KalitiduBojonegoro with $p$ value in the man whitney test of 0.005 in self esteem and 0.000 in stress levels and $p$ value the value of the Wilcoxon test is 0.025 in self esteem and 0.001 in the stress level, all of which are less than the error level $(\alpha=0.05)$. The effect of self help group on self esteem and stress level proves the change from before being treated in the intervention group, this proves that the treatment will be a stimulus in assessing a person's self-esteem and stress level with family members with depression.
\end{abstract}

Keywords: Self Help Group, Self Esteem, Stress Level

Accepted: October 13, 2019

Published : November 26, 2019

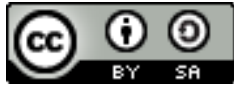

This is an open-acces article distributed under the terms of the Creative Commons Attribution-ShareAlike 4.0 International License.

\section{INTRODUCTION}

Mental health is still a significant health problem in the world, including in Indonesia. Until now the handling of mental disorders both at home and at the hospital has not been satisfactory and very varied. In general, families who have family members who are depressed will handle according to their perceptions and feel what they have done is a maximum effort to be able to curethesufferer 
According to WHO data (2016), there are about 35 million people affected by depression. The 2013 Riskesdas data shows the prevalence of emotional mental disorder which is indicated by symptoms of depression and anxiety for the age of 15 years and over reaching around 14 million people or $6 \%$ of the total population of Indonesia .Based on data from the Dinsos of East Java, people with mental disorders in East Java in 2016 reached 2,369 people. That number increased by750people. From the assessment study conducted in the mental health of Kalitidu Health Center, out of 10 families who have depressed family members 7 of them experienced a level of Strees and low self esteem.

The effects that arise in families that have family members Depression usually starts from an environmental response that feels disturbed by the presence of family members with depression, concerns about the future, financial limitations and feelings of loss, even feelings of grief where psychological stressors are continually generated which can cause frustration. Feelings rejected from the environment will cause low levels of strees and self esteem (Peplau\&Sulivan, 2013: 82).

One therapy that can be recommended for families of depressed patients who experience stress levels and low self esteem is group activity therapy. Support group therapy is a process of participation where there are sharing experiences, situations and problems focused on the principle of giving and receiving, applying self help groups, helping each other in developing individual knowledge and increasing self-respect (Chienet al, 2014).

\section{MATERIALS AND METHODS}

The research design that will be used in this study is to use True experimental design with preposttest design. Control groups and experimental groups were observed before intervention, then observed again after intervention, with the dependent variable stress and self esteem while the independent variable was Self Help. Group. This true experimental method is carried out to prove the effect of self help groups on self esteem and Stress levels in families with people with depression at the Poly psikiatry Health Center Kalitidu

The population in this study were families with depressed patients in psychiatric psychology of 54 families. The respondents in this study were 32 family respondents with depressed patients with sampling.Then analyzed techniques with Wilcoxon and mannwhitny test.

\section{RESULT}

1. Frequency distribution of the level of self esteem before intervention in the treatment group

Tabel 1 Frequency distribution of the level of self esteem before intervention in the treatment group

\begin{tabular}{lll}
\hline Level of self esteem & Total & $\%$ \\
\hline High & 7 & 43.8 \\
\hline Low & 9 & 56.2 \\
\hline Total & 16 & 100.0 \\
\hline
\end{tabular}

Tabel 1 show that there are 9 respondents $56.2 \%$ who have low self esteem before being given a self help group

2. Frequency distribution of stress levels before intervention in the treatment group

Tabel 2 Frequency distribution of stress levels before intervention in the treatment group

\begin{tabular}{lll}
\hline Stress Level & Total & $\%$ \\
\hline Light & 4 & 25.0 \\
\hline Medium & 9 & 56.2 \\
\hline Weight & 3 & 18.8 \\
\hline Total & 16 & 100.0 \\
\hline
\end{tabular}

Tabel 2. Showed that there were 9 respondents $56.2 \%$ had moderate stress levels before being given a self help group and 3 respondents $18.8 \%$ had severe stress levels before being given a self group 
3. Frequency distribution of the level of self esteem after intervention in the treatment group

Tabel 3 Frequency distribution of the level of self esteem after intervention in the treatment group

\begin{tabular}{lll}
\hline Self Esteem Level & Total & $\%$ \\
\hline High & 12 & 75.0 \\
\hline Low & 4 & 25.0 \\
\hline Total & 16 & 100.0 \\
\hline
\end{tabular}

Tabel 3 shows that there are 12 respondents $75 \%$ who have high self esteem after being given a self help group

4. Frequency distribution of stress levels after intervention in the treatment group

Tabel 4 Frequency distribution of stress levels after intervention in the treatment group

\begin{tabular}{lll}
\hline Stress Level & Total & $\%$ \\
\hline Light & 12 & 75.0 \\
\hline Medium & 4 & 25.0 \\
\hline Total & 16 & 100.0 \\
\hline
\end{tabular}

Tabel 4 shows that there are 12 respondents $75 \%$ who have mild stress levels after being given a self help group, 4 respondents $25 \%$ have moderate stress levels after being given a self help group.

5. Frequency distribution of the level of self esteem in the control group before being given treatment

Tabel 5 Frequency distribution of the level of self esteem in groups control

\begin{tabular}{lll}
\hline Tingkat Self Esteem & Total & $\%$ \\
\hline Medium & 8 & 50.0 \\
\hline Weight & 8 & 50.0 \\
\hline Total & 16 & 100.0 \\
\hline
\end{tabular}

Tabel 5 shows that there are 8 respondents each $50 \%$ who have moderate and severe self esteem in the control group

6. Distribution of the frequency of stress levels in the control group before being given treatment

Tabel 6 Frequency distribution of stress levels in the control group

\begin{tabular}{lll}
\hline Stress Level & Total & $\%$ \\
\hline High & 4 & 25.0 \\
\hline Low & 12 & 75.0 \\
\hline Total & 16 & 100.0 \\
\hline
\end{tabular}

Tabel 6 showed that there were 12 respondents $75 \%$ who had low stress in the control group and 4 respondents $25 \%$ with high stress

7. Frequency distribution of the level of self esteem in the control group after being given treatment

Tabel 7 Frequency distribution of the level of self esteem in groups control

\begin{tabular}{lll}
\hline Self Esteem Level & Total & $\%$ \\
\hline Medium & 8 & 50.0 \\
\hline Weight & 8 & 50.0 \\
\hline Total & 16 & 100.0 \\
\hline
\end{tabular}

tabel 7 shows that there are 8 respondents each $50 \%$ who have moderate and severe self esteem in the control group 
8. Frequency distribution of stress levels in the control group after being given treatment

Tabel 8 Frequency distribution of stress levels in the control group

\begin{tabular}{lll}
\hline Stress Level & Total & $\%$ \\
\hline High & 4 & 25.0 \\
\hline Low & 12 & 75.0 \\
\hline Total & 16 & 100.0 \\
\hline
\end{tabular}

tabel 8showed that there were 12 respondents $75 \%$ who had low stress in the control group and 4 respondents $25 \%$ with high stress

9. Analysis of self esteem before and after being given a self help group in the treatment group

Tabel 9 Analysis of self esteem before and after being given self help group in the treatment group

\section{Test Statistics ${ }^{\mathrm{b}}$}

Z

pre_test_self_help_group - post_test_self_help_group

$$
-2.236^{\mathrm{a}}
$$

Asymp. Sig. $\quad(2-$

tailed)

a. Based on negative ranks.

b. Wilcoxon Signed Ranks Test

Tabel 9 indicates that the condition of the respondent before being intervened with the self help group on self esteem with the Wilcoxon test value of 0.025 which means there is an influence of the intervention self help group on self esteem with an error value of $<0.05$.

10. Stress level analysis before and after being given self help groups in the treatment group Tabel 10 Analysis of stress levels before and after being given self help group in the treatment group

\begin{tabular}{ll}
\hline Test Statistics $^{\mathbf{b}}$ & \\
\hline & pre_test_self_help_group - post_test_self_help_group \\
$\mathrm{Z}$ & $-2.887^{\mathrm{a}}$ \\
Asymp. Sig. (2-tailed) & .004 \\
a. Based on negative ranks. & \\
b. Wilcoxon Signed Ranks Test
\end{tabular}

Tabel 10 indicates that the condition of the respondent after being intervened with the self help group at the level of stress with the Wilcoxon test value of 0.004 which means that there is an influence of the self help group intervention on the level of stress with an error value of $<0.05$.

11. Analysis of self esteem before and after being given a self help group in the control group Tabel 11 Analysis of self esteem before and after being given self help group in the control group

\section{Test Statistics ${ }^{b}$}

Z pre_test_self_help_group - post_test_self_help_group

Asymp. Sig. (2-tailed) 1.000

a. The sum of negative ranks equals the sum of positive ranks.

b. Wilcoxon Signed Ranks Test

Tabel 11 shows that the condition of the respondent before being intervened with the self help group on self esteem with the Wilcoxon test value is 1,000 which means there is no influence. 
12. Analysis of stress levels before and after being given a self help group in the control group Tabel 12 Analysis of stress levels before and after being given self help group in the control group Test Statistics $^{b}$

$$
\text { pre_test_self_help_group - post_test_self_help_group }
$$

Z

$.000^{\mathrm{a}}$

Asymp. Sig. (2-tailed) 1.000

a. The sum of negative ranks equals the sum of positive ranks.

b. Wilcoxon Signed Ranks Test

Tabel 12 shows that the condition of the respondent after being intervened with the self help group at stress level with the Wilcoxon test value is 1,000 which means there is no influence

13. Analysis of differences in self esteem before and after in the treatment and control groups

Tabel 13 Analysis of differences in self esteem before after beingiven self help group in treatment and control groups

\begin{tabular}{lll}
\hline Test Statistics $^{\mathbf{b}}$ & & \\
\hline & self_esteem & self_estreem_before \\
Mann-Whitney U & 56.000 & 104.000 \\
Wilcoxon W & 192.000 & 240.000 \\
Z & -3.138 & -1.099 \\
Asymp. Sig. (2-tailed) & .002 & .272 \\
Exact Sig. [2*(1-tailed & $.006^{\text {a }}$ & $.381^{\text {a }}$ \\
Sig.)] & \\
a. Not corrected for ties. & \\
b. Grouping Variable: self_help_group &
\end{tabular}

Tabel 13 shows that the condition of respondents there are differences in self esteem before and after being given intervention in the treatment group with the control group that is equal to 0.006 versus 0.381 .

14. Analysis of differences in self stress levels before and after treatment and control groups Tabel 14 Analysis of differences in stress levels before and after being given self-help groups in the treatment and control groups

\begin{tabular}{lll}
\hline Test Statistics $^{\mathbf{b}}$ & & \\
\hline & Stress level & Stress level before \\
Mann-Whitney U & 20.000 & 72.000 \\
Wilcoxon W & 156.000 & 208.000 \\
Z & -4.345 & -2.348 \\
Asymp. Sig. (2-tailed) & .000 & .019 \\
Exact Sig. [2*(1-tailed Sig.)] & $.000^{\text {a }}$ & $.035^{\text {a }}$ \\
a. Not corrected for ties. & \\
b. Grouping Variable: self_help_group & \\
\hline
\end{tabular}

Tabel 14 shows that the condition of respondents there are differences in stress levels before and after being given intervention in the treatment group with the control group that is equal to 0,000 versus 0.035

\section{DISCUSSION}

\section{A. Family Self Esteem Level After Being Given Self Help Group}

From the results of the study showed that there were 12 respondents $75 \%$ who had high self esteem after being given a self help group. At the age of 36-45 there are 11 respondents $34.4 \%$ 
have high self esteem, 11 women $34.4 \%$ have low self esteem, and 10 respondents $31.2 \%$ with the work of farmers have low self esteem.

Rosenberg (Mruk, 2013: 30) explains that individuals with high self esteem feel themselves valuable, respect themselves but do not admire themselves or expect others to admire them. Individuals with high self esteem tend to develop themselves and improve themselves

The average respondent after participating in the Self Help Group already felt that they were useful people, felt that they were of good quality, no longer felt as a failure, were able to do good things, had many things which they were proud of being positive about themselves, felt satisfied with yourself, feel useful for others. With the increase in Self Esteem families are able to appreciate the life they live without blaming what they experience when having families with people with depression, even they are able to develop themselves better without being burdened with the situation.

\section{B. Stress level of the family After giving the self help group}

From the results of the study showed that there were 12 respondents $75 \%$ who had a mild stress level after being given a self help group, 4 respondents $25 \%$ had moderate stress levels after being given a self help group. At the age of 36-45 years as many as 8 respondents $25 \%$ have mild stress levels, 9 female respondents $28.1 \%$ have mild stress, 8 respondents $25 \%$ with the category of farmers have moderate stress levels.

Things that are done part of coping (in Jusung, 2013). According to Colman (2014) coping is a process where someone tries to regulate the differences received between demands and resources that are assessed in a stressful state. Individuals of all ages experience stress and try to overcome them. Because the physical and emotional tension that accompanies stress causes discomfort, a person becomes motivated to do something to reduce stress.

From the facts above the family is able to be motivated to do something to reduce stress by creating effective coping mechanisms. The family is able to recognize stress, increase the body's reaction and make arrangements for stress by recognizing problems with oneself. This is able to reduce a person's stress level, from the level of severe stress to moderate and moderate stress to mild stres

\section{Self Esteem level and family stress level in the control group after being given a Self Help Group}

From the results of the study showed that there were 8 respondents each $50 \%$ who had moderate and severe self esteem in the control group and showed that there were 12 respondents $75 \%$ who had low stress in the control group and 4 respondents $25 \%$ with high stress.

According to Peplau, et all (2013), social self-esteem is a social relationship in groups providing opportunities for individuals to enjoy a variety of togetherness. Togetherness in various activities, interests, and attitudes that are often given by relationships in groups. This is what often develops into a sense of friendship and a sense of belonging and belonging to the group (sense of belongingness)

Not all problems can be solved by individuals. Once the individual is aware of the limitations of his abilities, then he tends to try to find information about the characteristics of the solution and the solutions available to him. This support is given by group members who are considered more competent or expert in providing assistance expected by group members.

From the facts above shows that, individuals with self-esteem and stress conditions with depression family stressors who do not get support to maintain coping mechanisms in the form of self help groups, tend not to show positive coping changes. Koping is the most important part of each individual to deal with various problems so that each individual can understand and solve problems and get a positive solution for the stressor faced. In addition, when positive family coping will also have a positive impact also for people with depression

\section{Self Esteem Level before and after being given Self Help Group}

Based on statistical tests using SPSS Wilcoxon Signed Ranks test between the pre test and post test values showed that the condition of the respondent before and after the intervention with the 
self help group on self esteem with the Wilcoxon test value of 0,025 with an error value of $<0.05$ then Ho is rejected which means that the results of the pre test and post test have significant differences. This shows that there is an effect of Self Help Group on family self esteem with depressed patients in the mental health clinic of the Kalitidu health center in Bojonegoro.

As we know that the respondents before joining the Self Help Group activities they still have a low level of self-esteem, but after participating in the Self Help Group they change because they already have a high level of self esteem

According to Randall (2013) Self Help Group is a place for someone to give each other and get emotional and practical support by exchanging information.

Self esteem occurs when there is a perception and communication between the researcher and the client's family. Then both of them bring together goals through the Self Help Group method. In this action or action the Self Help Group is raised and the reaction process, self-esteem and transaction are aimed at achieving the goal of self-esteem of the family with sufferers of depression. Self Help Group activities are checking in, presenting problems, clarifying problems, sharing proposals, planning actions and checking out so that self-esteem of families with depression can be achieved according to purpose

\section{E. Stress level before and after being given Self Help Group}

Based on statistical tests using SPSS Wilcoxon Signed Ranks test between the pre test and post test values showed that the condition of the respondent before and after the intervention with the self help group at stress level with the Wilcoxon test value of 0,004 with an error value of $<0.05$ then Ho is rejected which means that the results of the pre-test and post-test have significant differences. This shows that there is an effect of Self Help Group on family stress levels with depressed patients in the mental health clinic of KalitiduBojonegoro health center.

Respondents at the time before participating in the Self Help Group activities still had severe and moderate stress levels, but after participating in the Self Help Group they changed because they had mild stress levels

In the Self Help Group, individuals feel that there are similarities with each other such as in the age, needs and goals that can strengthen the group. In the Self Help Group there is no importance on the existence of an organizational structure, but among group members feel the responsibility for the success and failure of the group. In this Self Help Group, individuals find themselves (personal) and can develop their social sense in line with the development of their personality (Asmara, 2007 in Muslima 2013: 23).

Changes that occur before and after being given self help groups are very significant, from the results of the research above there is a decrease in stress levels after being given a self help group and an increase in Self Esteem after treatment. This is caused because in the process of implementing Self Help Group the family can support and problem solving techniques from facilitators and from other families

\section{F. The level of Self Esteem and family stress level in the control group before and after the self help group is given}

Based on the results of the study showed that the condition of the respondent before being intervened with the self help group on self esteem with the Wilcoxon test value of 1,000, which means there is no influence and shows that the condition of the respondent after intervention with the self help group at stress level with Wilcoxon test value of 1,000 also means that there is no influence because of the $\mathrm{p}$ value $>\alpha=(0.05)$.

According to Peplau, et all (2013), social self-esteem is a social relationship in groups providing opportunities for individuals to enjoy a variety of togetherness. Togetherness in various activities, interests, and attitudes that are often given by relationships in groups. This is what often develops into a sense of friendship and a sense of belonging and belonging to the group (sense of belongingness)

Based on this reality, individuals / families who get a stimulus from self help groups tend to show more improvement in coping mechanisms for self-esteem than groups that do not get treatment. Changes that occur before and after being given self help groups are very significant, from the 
results of the research above there is a decrease in stress levels after being given a self help group and an increase in Self Esteem after treatment. This is caused because in the process of implementing Self Help Group the family can support and problem solving techniques from facilitators and from other families

\section{G. The difference between self-esteem before and after the control group and the group given self-help group}

Based on the results of the study showed that the condition of respondents there are differences in self-esteem before and after being given intervention in the treatment group with the control group that is equal to 0.006 compared to 0.381 , which means there are differences in the level of the group treated with the untreated.

Rosenberg (Mruk, 2014: 30) explains that individuals with high self esteem feel themselves valuable, respect themselves but do not admire themselves or expect others to admire them. Individuals with high self esteem tend to develop themselves and improve themselves

Changes that occur before and after being given self help groups are very significant in the intervention group, from the results of the research above there is a decrease in stress levels after being given a self help group and an increase in Self Esteem after treatment. This is caused by the Self Help Group implementation process. families can support and problem-solving techniques from the facilitator and from other families. In the control group there is no change because the family does not get a supportive group from others so that the value of stress level and Self Esteem level has no change.

Families with depressed members are able to maintain their self-esteem with the touch of a selfhelp group, because families are willing to accept the reality that stressors like depressed family members are not issues that must be addressed in a drastic and protracted manner but they must think more positively to support their family members who are depressed. Regardless of any view by the environment, when he can think positively it will be more beneficial for himself and also family members who experience depression

\section{H. Differences in stress levels before and after the control group and groups given self-help groups}

Based on the results of the study showed that the condition of respondents there are differences in stress levels before and after being given intervention in the treatment group with the control group that is equal to 0.000 compared to 0.035 , which means that there are differences in the level of the group treated with the untreated.

Self Help Group according to Anonymous (2013). Develop empathy among fellow group members where fellow group members provide mutual reinforcement, form adaptive coping, provide support for fellow group members, Make better problem solving by sharing feelings and experiences providing opportunities for members group to talk about problems and choose what will be done, Increase awareness of fellow members so that a sense of security and prosperity is achieved

Based on the facts above, positive support in the form of a self help group will also have a positive impact on families with depressed members. When families look more at something that is more realistic and think critically it will eliminate negative assumptions so that it will fortify itself to avoid stress. Stress occurs in each individual because of a mindset that is not rheumatistic, rejection and an inadequate training process, which triggers individuals to get angry and reject the real conditions.

Changes that occur before and after being given self help groups are very significant in the intervention group, from the results of the research above there is a decrease in stress levels after being given a self help group and an increase in Self Esteem after treatment. This is caused by the Self Help Group implementation process. families can support and problem-solving techniques from facilitators and from other families In the control group there is no change because the family does not get a supportive group from others so that the value of stress level and Self Esteem level does not change. 


\section{CONCLUSION}

Based on the results of the study showed that there was an effect of Self Help Group on self esteem and stress levels of families with depressed patients at the mental health clinic at the health center of Bojonegoro.

\section{REFERENCES}

Chienet al.2014 TerapiModalitasKeperawatanPadaKlienPsikogeriatrik. Jakarta: Salemba Medika.

Colman (2014). konsep penatalaksanaan manajemen Stres . Jakarta: EGC

Crawford, John dkk. (2013). The Depression Anxiety Stress Scales (Dass): Normative Data And

Harper (2014) Self esteem management. Jakarta: Salemba Medika

Monks, Haditono.2013 ). Relaksasi Untuk Mengurangi Stres Yogyakarta: Gava Media

Peplau ,Sulivan. 2013 Terapi Modalitas Keperawatan Pada Klien Psikogeriatrik. .Jakarta: Salemba Medika

Randall (2013) Self Help group terapy . Jakarta: EGC

Rosenberg,owens(guidon,2013) Self esteem management .Jakarta: Salemba Medika. 